\title{
PIBID: A DIMENSÃO SOCIÓLÓGICA PRESENTE NA APRENDIZAGEM DOS ALUNOS NO INÍCIO DA ESCOLARIDADE
}

\author{
Camila Alves Da Silva Rodrigues Pimentel ${ }^{1}$ \\ Vera Lúcia Catoto Dias ${ }^{2}$ \\ Anamaria da Silva Martin Gascón Oliveira ${ }^{3}$
}

Resumo: O presente artigo tem o objetivo de analisar por meio de intervenção pedagógica com jogos sonoros, como a função social da escola influencia na aprendizagem de alunos no inicio da escolaridade. A metodologia centrou-se em pesquisa bibliográfica/documental seguida de pesquisa de campo pela aplicação de instrumento sondagem de leitura/escrita realizada com alunos do $1^{\circ}$ ano do ensino fundamental em uma escola pública estadual, localizada no município de São José dos Campos, São Paulo. Esta proposta justifica-se por expor como a função social da escola pode influenciar no sucesso dos alunos nos anos iniciais. A análise de resultados fundamentada em Pierre Bourdie para a identificação do funcionamento da intervenção.

Palavras-chave: Ensino; Escola; Aprendizagem; Contexto social.

\footnotetext{
1 Pedagogia/Universidade do Vale do Paraíba - UNIVAP/Faculdade de Educação e Arte-FEA. E-mail: milapimentel@hotmail.com.

2 Pedagogia/Universidade do Vale do Paraíba - UNIVAP/Faculdade de Educação e Arte-FEA. E-mail: vcatoto@univap.br.

3 Pedagogia/Universidade do Vale do Paraíba - UNIVAP/Faculdade de Educação e Arte-FEA. E-mail: gascon@univap.br.
} 